\title{
The Experimental Study of Performance Ejecting Dust Collector in Mine
}

\author{
Haizhan Li \\ School of Energy and Power Engineering \\ Jiangsu University \\ Zhenjiang,China \\ liseawar@163.com \\ Zhuliang Wang \\ School of Energy and Power Engineering \\ Jiangsu University \\ Zhenjiang,China \\ wangzhul@163.com
}

\author{
Hongyu Wang \\ School of Energy and Power Engineering \\ Jiangsu University \\ Zhenjiang,China \\ 535186924@qq.com
}

\begin{abstract}
For mining gas outburst coal dust pollution problems caused by dry drilling, this paper proposes a new mine wet compressed air ejecting dust collector. The energyefficient experimental project of compressed air ejecting dust collector was designed, and tested the performance of the dust collector in the experiment. To ensure the structural parameters unchanged, testing the change of import static pressure, ejecting air flow, ejecting ratio and noise of different pipe lengths dust collector with compressed air pressure respectively. The results showed that: the ejecting performance parameters of the length of $1000 \mathrm{~mm}$ pipes dust collector is better than the dust collector which the length is $1300 \mathrm{~mm}$. When compressed air pressure are $0.25 \mathrm{MPa}$ and $0.3 \mathrm{MPa}$, the total dust removal efficiency of the dust collector which the length is $1000 \mathrm{~mm}$ pipes reached $97.6 \%$ and $97.9 \%$ respectively, are reflect the better performance of dusting.
\end{abstract}

Keywords-mine;dust collector;ejecting performance, dust collection efficiency.

\section{INTRODUCTION}

With the increase of China's energy demand, coal mining has intensified, domestic gas outburst coal mining safety issues have become increasingly severe. For some soft prominent seam, use only dry drilling, compressed air blowing dust technology to make coal powder and compressed air produced when drilling a hole wall along the gap between the drill pipe and the discharge pipe[1].This will produce a lot of dust, resulting in face dust concentration is too large, contaminated working environment.In wind slagging process, fine dust is more, these light-weight and surface area larger than the other dust, and therefore has a strong adsorption capacity of the air[2], so that dust is hard to settle in the form of a floating state in the air tunnel, endangering the operating personnel physical health, can also cause severe major coal mine accidents.Thus, for the dust pollution problems and governance of dry drilling exists, needed a new technology to further reduce the amount of dust generated during dry drilling in order to ensure the face of dust concentrations within national safety regulations, thereby to provide security for miners.Currently, there is a common way of opening the orifice dust spray, spray the whole section, add the right amount of water and the wind pressure pumping dust and other technology[3,4]. But the above manner dust removal effect is not ideal, filter structure is more complex, more difficult to install, and therefore are not widely used in the mine.Based on the principle of injection technology theory and Venturi tubes precipitator[5-7], compressed air ejector dust technology is proposed to effectively solve the problem of traditional precipitator dust in the mine encountered.

\section{EXPERIMENTAL SETUP}

\section{A. The Experimental Design}

The innovation of bench is put the original independent gas supply system and water supply systems into one system in designing and building process, thus eliminating the need for many of the components of water supply systems, while simplifying the test-bed structure, on the other hand by eliminating the high-energy pumps, energy saving efficiency is significant. The surge tank can not only ensure stable compressed air pressure, can also provide the necessary pressure of water in experiments. Fig.1 is dust ejector experimental setup. When conducting the no spray experiment, screwing the waterway valve closed, high-pressure gas by compressor provided into surge tank, the surge tank to adjust the pressure at the outlet valve, the pressure of the gas adjust to the desired pressure and testing no spray ejector performance. When there is spray and dust ejector performance test experiment, open waterway screwed valve, fine-tuning by a needle valve, the amount of water needed to be transferred. To prevent nozzle clogging, the system set up Y-type filters, the device can be manually operated to achieve timing backwash water filtration device.This fully guarantee the quality of the experimental water, eliminating the need for cleaning nozzles work. 


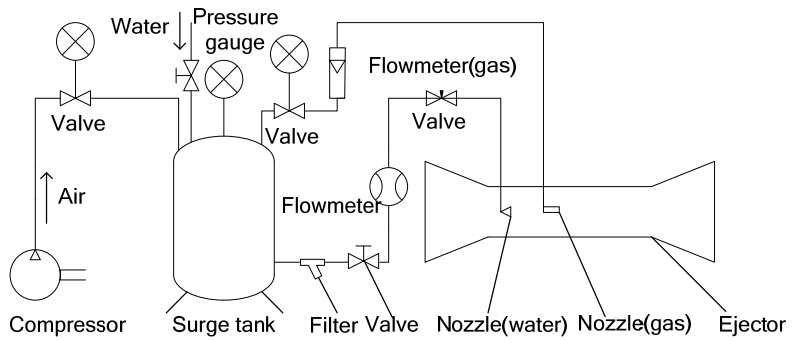

Figure 1. Experimental setup

\section{B. Laboratory Instruments and Measurement Parameters}

Experiment measuring instruments needed major hot ball anemometer, noise analyzer, empty box barometer, dry / hygrometer, gas flowmeter and pressure gauges and other measuring instruments. Among them, the hot ball anemometer is mainly used to measure wind speed ejector inlet ; noise Analyzer tool is mainly used to measure the size of the noise generated by the outlet premises; gas flowmeter is used to measure the flow rate of the working gas; pressure gauge used to measure the pressure of the working gas; empty box barometer and dry / hygrometer used day of the experiment of measuring the atmospheric conditions.

\section{RESUlTS AND DisCUSSION}

\section{A. The Ejecting Performance Analysis of Dust Collector}

The experiment atmospheric conditions were: atmospheric pressure: $101450 \mathrm{~Pa}$; temperature: $23{ }^{\circ} \mathrm{C}$; humidity: $21.9{ }^{\circ} \mathrm{C}$. Pipe1 represents the pipe length is $1000 \mathrm{~mm}$ dust ejector, Pipe2 represents a length of $1300 \mathrm{~mm}$ pipe dust ejector. A, B , C and D represent pipe1 no spray, pipe1 spray, pipe2 no spray and pipe2 spray respectively. Experiments on spray and no spray processing in case of import static pressure, ejecting air flow, ejecting ratio and noise measurements and calculations were carried out, results are as follows:

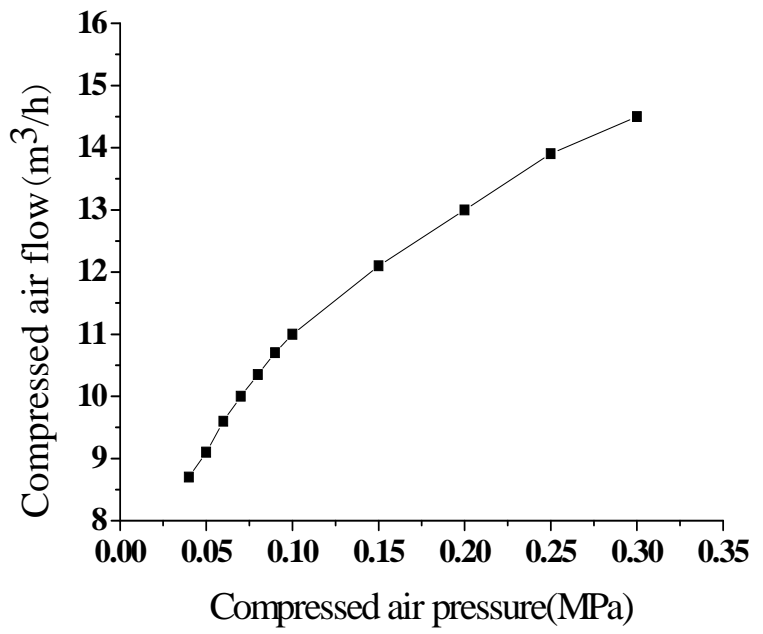

Figure 2. Compressed air flow change with compressed air pressure

As can be seen from Fig. 2, the compressed air flow increases with increasing of compressed air pressure, when the compressed air pressure reached $0.1 \mathrm{MPa}$, the increasing rate of compressed air flow tends to slacken, which in line with the theoretical calculations. As for how much compressed air pressure and compressed air flow in the actual application process will be based on the amount of dust and gas drilling slagging determine the number of nozzles.

As can be seen from the experimental results from Fig. 3 and Fig .4, with the increase of the pressure of the gas pressure, static pressure and ejecting air flow of two different dust ejector four conditions were tested to increase.The reason is with increasing gas pressure in the nozzle pressure, nozzle outlet velocity will increase, due to structural reasons peculiar to the Laval tube, which will be at the rear of the compressed air nozzle (i.e., a tapered inlet port to the nozzle) will form a very large negative pressure, and with the pressure of the compressed gas pressure increases, along with import static pressure increases, so that the gas volume at the inlet section is inhaled into dust ejector and forming a certain section of the inlet air velocity. Ejecting air flow was obtained by imports velocity and inlet cross-sectional area multiplying, so ejecting air flow increases. When there are spray, while the water in the dust collector in the forward movement with the working gas, this will consumes part of the kinetic energy, thereby reducing the high velocity gas stream velocity which led to their import static pressure and ejecting air flow decreases. The finally result is that the performance of condition which there no spraying is lower than the case when no spray. When the length of the pipes to increase, the resistance of the working gas in the tube increases, leading to a part of the kinetic energy is dissipated, so the ejecting performance of the two conditions of the pipe 2 is slightly lower than pipe1.

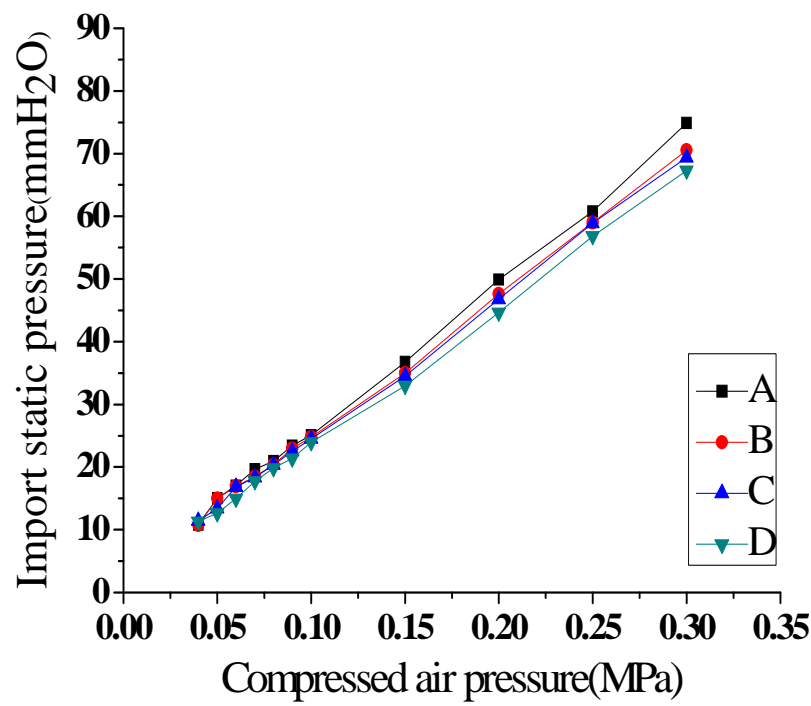

Figure 3. Import static pressure chang with compressed air pressure 


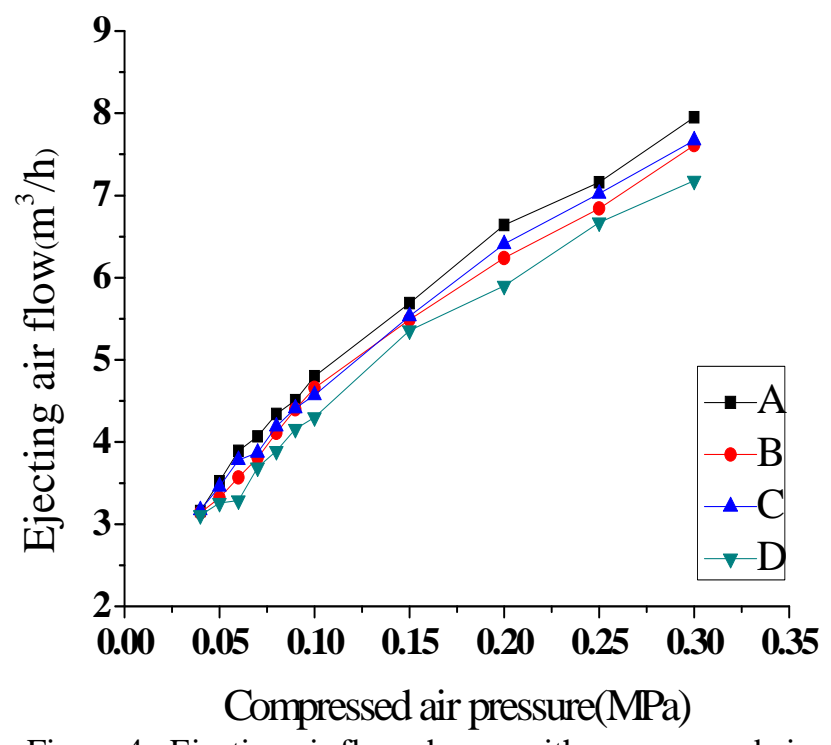

Figure 4. Ejecting air flow change with compressed air pressure

Ejecting ratio is the amount of working fluid that can be sucked by the ejector entrained flow body, i.e., the ratio of ejecting air flow and the flow of compressed air[8], which is another important parameter to evaluate dust ejector performance. For the same compressed air pressure the larger ejecting ratio, ejector better. Fig .5 shows the size of ejecting ratio of four conditions.

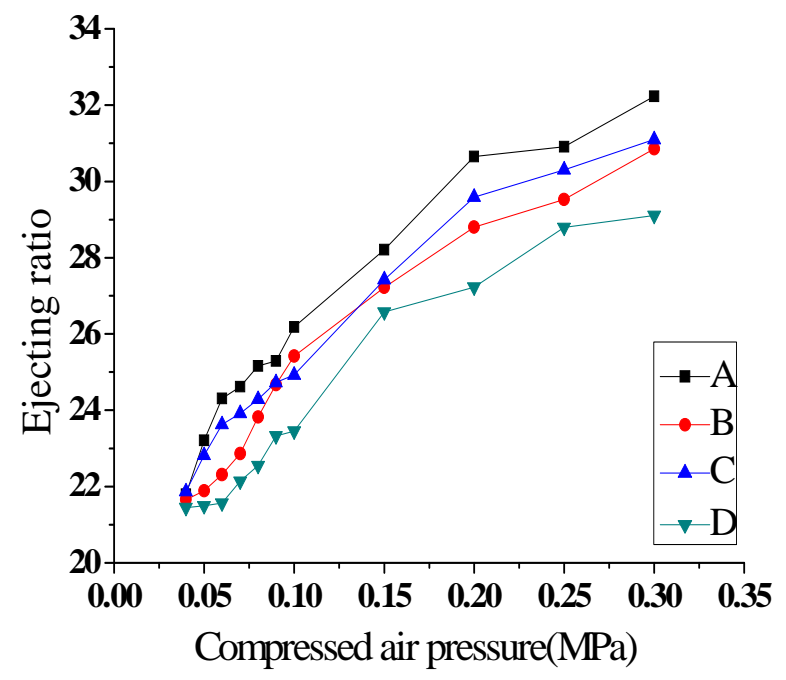

Figure 5. Ejecting ratio change with compressed air pressure

As it is a high pressure gas jetting, so the dust collector will be the formation of noise, if the noise is too large, in the actual process have a certain hazards for the on-site operating personnel[9]. Therefore, the process of this experiment, we chose to the noisiest locations were measured with noise analyzer, measuring tap in the dust ejector outlet of the $0.5 \mathrm{~m}$ range, measured three points, the average value of the work performed under noise conditions. The noise of four conditions formed are shown in Fig .6. Noise added when the spray is smaller than the no spray conditions. For how to further reduce noise, considering at the outlet of the precipitator plus a muffler.

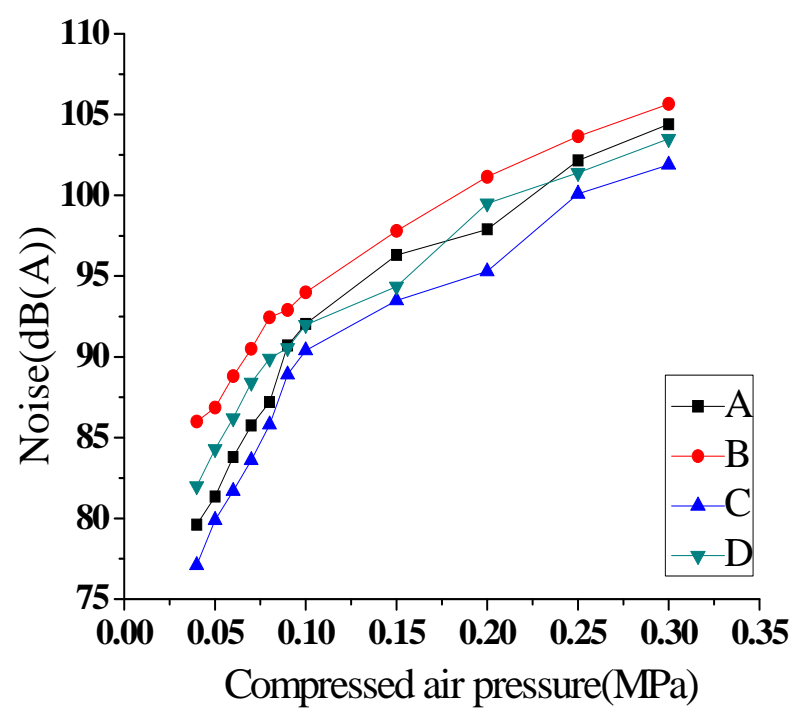

Figure 6. Noise change with compressed air pressure

\section{B. Dusting Results}

Finally, the dust collection efficiency is measured. By isokinetic sampling method carrying on isokinetic sampling in the imports and exports. The principle is to ensure that the sampling rate of the mouth and dust wind speed pipeline agreement. The dust collection efficiency can be gained by calculating using sampling weight of the Membrane. The calculating formula (1) , (2) and (3) [10] as follows:

$$
\begin{aligned}
& c=\frac{m_{2}-m_{1}}{q} \times \frac{3600}{t} \\
& \eta=\frac{c_{1}-c_{2}}{c_{1}} \times 100
\end{aligned}
$$

$\bar{\eta}=\frac{\eta_{1}+\eta_{2}+\eta_{3}}{3}$

Where, $\mathrm{m}_{1}$ and $\mathrm{m}_{2}$ are the filter quality of the sample before and after respectively, $\mathrm{q}$ is the isokinetic sampling flow, $\mathrm{t}$ is sampling time, $\mathrm{c}_{1}$ and $\mathrm{c}_{2}$ are calculating the concentration of dust, $\eta$ is dust collection efficiency. Inlet and outlet represent import and export position of the dust collector respectively. During the experiment the sample flow are measured in the import and export position. When compressed air pressure is $0.25 \mathrm{MPa}$, the sample flow are $1.69 \mathrm{~m}^{3} / \mathrm{h}$ and $2.07 \mathrm{~m}^{3} / \mathrm{h}$ in the import and export respectively. When compressed air pressure is $0.3 \mathrm{MPa}$, the sample flow are $2.15 \mathrm{~m}^{3} / \mathrm{h}$ and $2.41 \mathrm{~m}^{3} / \mathrm{h}$ in the import and export respectively. Three times were sampled for each condition in different location. Sampling time for each measuring point is 60 seconds. The Collection efficiency have gained by calculating with formula (1) , (2 and (3). Test results are as the TABLE I: 
TABLE I: Dust Collection Efficiency of Ejecting Dust Collector

\begin{tabular}{|c|c|c|c|c|c|c|}
\hline \multirow{2}{*}{$\begin{array}{c}\text { Compressd Air Pressure } \\
\text { (MPa) }\end{array}$} & \multicolumn{2}{|c|}{ Inlet } & \multicolumn{2}{|c|}{ Outlet } & \multirow{2}{*}{$\begin{array}{l}\text { Dust Collection } \\
\text { Efficiency }(\%)\end{array}$} & \multirow{2}{*}{$\begin{array}{c}\text { Average Dust } \\
\text { Collection } \\
\text { Efficiency } \\
(\%)\end{array}$} \\
\hline & $\begin{array}{c}m 1 \\
(m g)\end{array}$ & $\begin{array}{c}m 2 \\
(m g)\end{array}$ & $\begin{array}{c}m_{1}^{\prime} \\
(\mathrm{mg})\end{array}$ & $\begin{array}{l}m_{2}^{\prime} \\
(m g)\end{array}$ & & \\
\hline \multirow{3}{*}{0.25} & 76.2 & 94.0 & 75.0 & 75.5 & 97.5 & \multirow{3}{*}{97.6} \\
\hline & 75.0 & 85.1 & 73.6 & 73.8 & 98.2 & \\
\hline & 74.0 & 85.1 & 74.9 & 75.3 & 97.0 & \\
\hline \multirow{3}{*}{0.3} & 75.9 & 111.3 & 74.5 & 75.3 & 98.0 & \multirow{3}{*}{97.9} \\
\hline & 74.4 & 97.7 & 75.4 & 75.9 & 98.1 & \\
\hline & 74.7 & 92.9 & 73.9 & 74.4 & 97.6 & \\
\hline
\end{tabular}

MT159-2005 "universal technical specification for dust collection enginery for mine" set that in wet dust removal efficiency greater than 97\%[11]. As can be seen from the Table1, two working conditions of dust collector dust collection efficiency of the total concentration has reached more than 97\%, to meet MT159-2005 "universal technical specification for dust collection enginery for mine" in the dust removal efficiency requirements has a good effect of dusting.

\section{CONCLUSIONS}

Through the different pipe lengths dust ejector experiment respectively, obtained with the increase of the working gas pressure, the performance parameters of dust ejector also increased, and the performance of the pipe length is $1000 \mathrm{~mm}$ of dust ejector is better than the length of pipe is $1300 \mathrm{~mm}$ dust ejector. When compressed air pressure are $0.25 \mathrm{MPa}$ and $0.3 \mathrm{MPa}$, the total dust removal efficiency of the dust collector which the length is $1000 \mathrm{~mm}$ pipes reached $97.6 \%$ and $97.9 \%$ respectively, is better than the traditional wet scrubber.

\section{REFERENCES}

[1] Xu-dong Ding and Bai-shun Wang, Design and Application of Pressure-gas Ejecting Orifice Dust Collector. Journal of Coal Technology, 30(12), pp.72-73, 2011.
[2] Shuai Wu, Sheng-qiang Yang,Jian-Bo Wang and Jie Liu, Applied Study on Dust Reduction and Control Technology with High Pressure Air Jet Spray. Journal of Coal Engineering, 43(4), pp.6466, 2011.

[3] Zoran S. Nikolic. Numerical simulation of gravity induced skeletal settling during liquid-phase sintering. Journal of Mathematical and Computer Modelling, 51, pp.1146-1153,2009.

[4] Karl Willian Felson, Experimental investigation of an ejector scramjet RBCC at mach 4.0 and 6.5 simulated flight conditions, The University of Alabama in Huntscille,(03)2002.

[5] Hong-xin Lu, Theory and Application of Jet Technology, Wuhan: Wuhan University Press,2004.

[6] Y. Bartosiewicz and Zine Aidoun. Numerical and experimental investigations on supersonic ejectors, Journal of Heat and Fluid Flow , 28(26),pp.56-70,2005

[7] Li-ning Huang and Jin-xing Hang, Dust Collection System of Pneumatic Drilled Borehole Applied to Longtan Miner. Journal of Coal Engineering, 46(1), pp.68-69, 2014.

[8] Kang-jian Wang and Kai Zhang, Application of Water-soluble Type Cleaner in Drilling Blowout Preventer. Journal of Coal Safety, 5(37), pp.120-131 2014.

[9] Sheng-jun Guo, Development and Application on Pneumatic and Wet Type Dust Collector in Mine, Journal of Coal Science and Technology, 40(5), pp.74-76, 2012.

[10] Zhong-fei Ma and Fu-qing Wang, The Dust Suction and Removal Test Research on Swirling Water Jet. Journal of Metal Mine, 33(1), pp.156-157, 2012.

[11] Xiao-dong Xiang, Dust Theory and Technology, Beijing: Metallurgical Industry Press,2013. 